\title{
Epistemic Injustice in Social Cognition
}

DOI:

10.1080/00048402.2018.1459754

\section{Document Version}

Accepted author manuscript

Link to publication record in Manchester Research Explorer

\section{Citation for published version (APA):}

Buckwalter, W. (2019). Epistemic Injustice in Social Cognition. Australasian Journal of Philosophy, 97(2), 294-308. https://doi.org/10.1080/00048402.2018.1459754

\section{Published in:}

Australasian Journal of Philosophy

\section{Citing this paper}

Please note that where the full-text provided on Manchester Research Explorer is the Author Accepted Manuscript or Proof version this may differ from the final Published version. If citing, it is advised that you check and use the publisher's definitive version.

\section{General rights}

Copyright and moral rights for the publications made accessible in the Research Explorer are retained by the authors and/or other copyright owners and it is a condition of accessing publications that users recognise and abide by the legal requirements associated with these rights.

\section{Takedown policy}

If you believe that this document breaches copyright please refer to the University of Manchester's Takedown Procedures [http://man.ac.uk/04Y6Bo] or contact uml.scholarlycommunications@manchester.ac.uk providing relevant details, so we can investigate your claim.

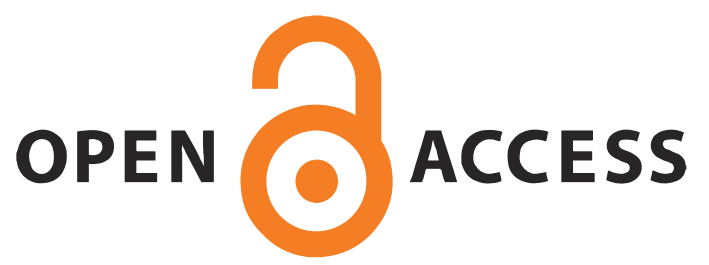




\title{
Epistemic Injustice in Social Cognition*
}

\author{
Wesley Buckwalter \\ wesleybuckwalter@gmail.com
}

Silencing is a practice that disrupts linguistic and communicative acts but its relationship to knowledge and justice is not fully understood. Prior models of epistemic injustice tend to characterize silencing as a symptom that follows as a result of underrepresenting the knowledge of others. In this paper, I advance a model of epistemic injustice in which the opposite sometimes happens. Drawing on recent work in experimental cognitive science, I argue that silencing can cause misrepresentations of knowledge and, subsequently, epistemic injustice to occur. Drawing on recent work in epistemology, I also argue that according to some leading theories, silencing potentially causes ignorance by depriving individuals and communities of knowledge itself. These findings expand our understanding of silencing in social practice, contribute a broader model of epistemic injustice for research at the intersection of ethics and philosophy of mind, and have implications for leading theories of knowledge in epistemology.

Keywords: silencing; speech acts; knowledge; assertion; norms; mental states

\footnotetext{
${ }^{*}$ Forthcoming in Australasian Journal of Philosophy. Please cite the published version if possible.
} 


\section{Introduction}

In recent years philosophers of language have begun focusing on how their research can be applied to illuminate practical matters of ethical and social concern [McGowan and Maitra 2009; Stanley 2015; Bolinger 2017]. One important discovery in this line of research is that in addition to injustice in the social or legal realms, there is also a closely related but distinct type of injustice in the intellectual realm [Fricker 2007; Dotson 2011; Alcoff 2012; Anderson 2012; Dotson 2014]. This type of injustice is called "epistemic injustice". It refers to the wrongs done to persons in their capacity as intellectual agents, and specifically, in their capacity as knowers. Because this category is so broad, there are several potential social and cognitive mechanisms by which epistemic injustice might occur, for example, through impeding one's ability to collect evidence, give testimony, form beliefs, or receive recognition for intellectual achievements (for an overview of potential biases, see Origgi [2012]). The focus of this paper is on epistemic injustice that occurs specifically in connection with one particular mechanism known as silencing.

Silencing is the act of interfering with or preventing others from speaking, communicating, or being heard [Langton 1993; Hornsby 1995; Maitra 2009; Dotson 2011]. Interfering with communication might not always be unjust, but it often can be. For example, many theorists have argued that silencing is unjust by observing that it is often motivated by prejudicial attitudes that differentially target vulnerable populations and members of marginalized groups [Collins 2000; Fricker 2007; Tuana 2009; Dotson 2011; Peet 2017]. Others have argued that silencing is unjust because of the serious epistemic, moral, and legal consequences it promotes, for example regarding health care, pornography, oppression, and consent [MacKinnon 1987; Langton 1993, 1998; Mcgowan 
2003; West 2003; Tuana 2009]. In light of this research it has become clear that there is a pressing need to better understand silencing, both its effects in the applied social realm, as well as how it might inform and expand current theorizing on communication at the intersection of ethics, epistemology, and philosophy of language.

Influential prior work on epistemic injustice, most famously by Miranda Fricker and Kristie Dotson, has provided extensive models of how silencing can be a symptom of epistemic harm. Call this the "symptom model" of epistemic injustice. According to the symptom model, silencing can be an effect of certain epistemic evaluations. According to Fricker's account of "testimonial injustice", for example, "prejudice on the hearer's part causes him to give the speaker less credibility than he would otherwise have given," which can lead to silencing them [Fricker 2007: 4]. Dotson characterizes a type of silencing called "testimonial quieting" whereby "epistemic violence" occurs when an "audience fails to identify a speaker as a knower" [Dotson 2011: 242]. In other words, the antecedent ignorance judgments that listeners make about speakers lead them to reject their testimony, which causes silencing to occur. As a result of incorrectly identifying the knowledge a speaker has, the listener might dismiss the speaker's evidence, undermine or reject their credibility, refuse to listen to them over others, or stop communicating with them entirely. This model of epistemic injustice illustrates ways that silencing could follow as a result of representing knowledge.

This paper advances a compatible but distinct model of epistemic injustice involving silencing working in the opposite direction. Call this the "causal model" of epistemic injustice. According to the causal model, the practice of silencing constitutes epistemic injustice by causing certain mental state representations of knowledge. In other 
words, the impact that antecedent acts of silencing have on speakers and listeners can lead us to subsequently deny knowledge to them and, in some cases, this can potentially deprive individuals or communities of knowledge itself.

There are many ways in which interfering with communicative acts could potentially limit what others know. One straightforward way this could happen is when silencing literally prevents the spread of information. According to some policies in Canada during the Harper government, for example, some scientists were forbidden from speaking to the press or public about their research [Zhang 2017]. Similar policies of the Trump administration in the United States may limit what information government officials at the Environmental Protection Agency and Department of Agriculture can communicate to the public [Maron 2017]. If scientists or officials cannot inform the public about climate change, for example, then it is easy to see how silencing could contribute to lower public knowledge about this or related scientific discoveries.

However silencing may also cause epistemic injustice in more subtle ways, rooted in the mechanisms by which we represent and attribute knowledge to others [Langton 2015; Stanley 2015]. The goal of this paper is to contribute to our understanding of these subtler connections between language and knowledge in theory of mind by modelling how this happens. To do this, I begin by introducing three types of silencing in speech act theory. I then present research on knowledge representation in social cognition and argue that it supports the causal model of epistemic injustice across each type of silencing. I then discuss the implications of this model in epistemology for the linguistics and metaphysics of knowing and argue that on several leading theories, silencing not only causes knowledge representation on the psychological level, but also may literally cause ignorance and risk 
limiting knowledge itself. I conclude by discussing these findings in the broader context of ethics and social practice.

\section{Silencing Prevents Action}

Silencing is a practice that disrupts speech and communicative acts. Within this broad description, there are several types and manifestations of silencing. To help isolate the causes and effects of silencing in social practice, theorizing typically follows divisions of action in speech act theory. This approach is famously pioneered over the last twenty years by philosophers Rae Langton and Jennifer Hornsby, characterizing different forms of silencing by their association with different linguistic or communicative acts [Langton 1993; Hornsby and Langton 2009]. Particularly, it has become standard to study silencing as it relates to one dominant taxonomy in philosophy of language distinguishing locutionary, illocutionary, and perlocutionary acts (see Austin [1975]; Turri [2012], for criticism see Finlayson [2014]). Although broad, this provides initial categories with which to begin identifying distinct types of silencing. In what follows, I sketch this broad taxonomy of acts ultimately deriving from Austin, while attempting to remain neutral about their finer points debated in contemporary speech act theory.

A first act type is the locutionary act. A locutionary act is the linguistic act of saying something meaningful in a language. In a spoken language, this is the act of uttering words that satisfy basic grammatical and semantic conventions of that language. For example, simply uttering the sentence "that person is guilty of a crime" is a locutionary act in virtue of satisfying the basic grammatical and semantic conventions of English. When someone utters those words, they have completed a locutionary act. 
Corresponding to the locutionary act is locutionary silencing. Following Langton [1993], this occurs when speakers are prevented from completing locutionary acts by uttering words. This type of silencing can occur when speakers are gagged or otherwise physically restrained, or when intimidation, coercion, or other threats deter or prevent individuals from speaking. Individuals might be silenced in this way when, for example, they are discouraged from speaking due to fear of retaliation or other harmful consequences of acting. Consider again the example of saying "that person is guilty of a crime". One can imagine many different types of locutionary silencing that could interfere with or deter someone from making such an utterance, from financial threats such as losing one's job or health insurance to physical violence in retaliation for coming forward. When individuals are prevented from speaking in these ways, they have been locutionarily silenced.

A second type of act is the illocutionary act. An illocutionary act is the speech act that you make by uttering words in a conversational context. To see this, consider the different moves you can make in different conversational exchanges by saying the very same words "yes I do" in different contexts. In answer to the question "do you swear it to be true?" for example, that utterance might constitute a promise. In other contexts, though, the same utterance could be used to guarantee something, recant or deny something, or to apologize for something. When you make these conversational moves with your words, such as promising, apologizing, guaranteeing, recanting, denying, or apologizing, you complete an illocutionary act.

Corresponding to the illocutionary act is illocutionary silencing. Again, following Langton [1993], this form of silencing can occur when individuals and groups are prevented from making certain kinds of conversational moves with their utterances that 
they intend to in specific contexts. There is some debate about what is required to successfully complete an illocutionary act and whether or to what extent this requires audience recognition [Bird 2002; Maitra 2009]. This debate notwithstanding, however, this kind of silencing is perhaps most straightforwardly demonstrated in highly institutionalized contexts, when, for example, governments pass laws restricting who can marry, give testimony, or enter into legal contracts. In such contexts, anyone might be able to utter the phrase "yes I do". Nonetheless, unjust laws restrict the kinds of conversational moves that individuals can make when they utter those words, namely, whether the utterance counts as a legal promise or legal marriage. In other words, by failing to recognize these utterances as such, governments can prevent speakers from being able to complete specific speech acts with their words, such as promising. When individuals are prevented from making speech acts, they have been illocutionarily silenced.

A third type of act is the perlocutionary act. A perlocutionary act is the act of affecting an audience with your linguistic and speech acts as you intended to. In asserting "that person is guilty of a crime", for example, you might intend your audience to be many things as a result. You might intend to inform them that this is true. Or you might intend to alert them, persuade or convince them, or galvanize them to act in such a way that would make sense given that the person is guilty. When your speech has the intended effect on your audience, such as having informed, alerted, persuaded, convinced, or galvanized them, you completed a perlocutionary act.

Corresponding to the perlocutionary act is perlocutionary silencing (see also Dotson [2011] on "testimonial smothering"). This form of silencing can occur when speakers successfully complete locutionary and illocutionary acts, such as making an 
assertion, for example, but when such acts fail to have the effect on their audience that the speaker intended. Because the category of perlocutionary action is so broad (for discussion, see Turri [2012]), not all forms of perlocutionary failure will count as silencing. For example, not all failures to win arguments by convincing audiences of something count as perlocutionary silencing. Instead, the term is typically reserved for conditions in which speakers fail to complete perlocutionary acts as a result of being denied some level of appropriate communicative cooperation from an audience. ${ }^{1}$ What constitutes "appropriate" is open for debate among theorists, but there are broad strokes of agreement about what is required for a minimum standard in cooperative communicative exchanges. For example, suppose again that I intend to alert you that a person is guilty of a crime. Whether my assertion succeeds in my conversational goal requires, among other things, minimal communicative cooperation on your part. At the very least, you must not plug your ears to prevent hearing words. You must recognize that I am attempting to provide you with information, as opposed to, say, reciting the lines of a novel or playing a practical joke on you. And you must extend some level of honest engagement with the evidence. When these forms of basic communicative cooperation are not present, and the assertion has not succeeded in its intended effect of alerting you, perlocutionary silencing has occurred.

1 There is ongoing debate concerning the related question of "audience uptake" in determining illocutionary versus perlocutionary success ([Austin 1975; Alston 2000; Bird 2002; De Gaynesford 2009], see also Wieland [2007: 455] regarding silencing and consent). 
To review, silencing is a practice that limits or prevents speech and communicative action. There are several types of silencing that correspond to different act types in speech act theory. Each type involves preventing a speaker from completing a certain kind of action. The causal model of epistemic injustice claims that epistemic injustice occurs when silencing causes certain representations of knowledge. The question then arises, what does preventing someone from completing different kinds of acts have to do with what they actually know?

\section{Actionability Causes Knowledge Representation}

Many philosophers have thought that action has a great deal to do with knowledge. The question of their relation is a foundational one in epistemology that weaves its way through the history of philosophy. William James, for example, thought cognition was deeply connected to action and perhaps that cognition was even partially constituted by actionability. He wrote that "it is far too little recognized how entirely the intellect is built up of practical interests," and that, "in the lower forms of life no one will pretend that cognition is anything more than a guide to appropriate action" [James 1879: 18]. Other philosophers, such as John Locke related actionability not only to cognition generally but to knowing specifically. Locke thought that the "notice we have by our senses...deserves the name of knowledge," because it gives us notice of things that "serve our purpose well enough," for governing our actions [Locke 1690 1975: book 4.11.8].

Practical features of an agent's situation also play central roles across several leading theories of epistemology. For instance, some theorists have claimed that knowledge is constituted partly by practical factors that are unrelated to truth, such as how much is at 
stake, the consequences of error, or whether a proposition is actionable in the course of everyday decision-making [Hawthorne 2004; Stanley 2005; Fantl and McGrath 2009]. Others have argued that "know" is context sensitive expression associated with different evidential standards in different contexts and that certain practical interests can affect those standards [Cohen 1999; DeRose 2009]. Still other philosophers have argued that knowledge plays an important normative role in licensing activities, such as assertion, practical reasoning, or proper courses of action [Unger 1975; Williamson 2000; Turri $2016 a]$.

These leading theories in epistemology have inspired a wave of empirical research in cognitive science experimentally investigating the link between knowledge and practice in social cognition. This research has confirmed the existence of several powerful psychological associations between assessments of knowledge, actions, and assertions. For instance, researchers have demonstrated direct causal relationships between assessments of how someone should act in various conversational contexts ("actionability") and judgments about what that person knows [Turri, Buckwalter, and Rose 2016; Turri and Buckwalter 2017]. Researchers have demonstrated that practical features of a situation can influence a broad range of epistemic assessments, including knowledge [May et al. 2010; Pinillos 2012; Sripada and Stanley 2012; Buckwalter and Schaffer 2015; Turri, Buckwalter, and Rose 2016], but also belief and confidence judgments [Turri 2017]. Researchers have built a strong case that knowledge sets the standard for assertion, pedagogy, and instructional demonstration [Turri 2013; Buckwalter and Turri 2014; Turri 2016a]. Researchers have even shown that judgments about vision, and specifically, 
judgments about what an agent thinks they see are sometimes caused by judgments about what an agent knows [Turri 2016b].

Two empirical advances connecting knowledge and action are particularly relevant for studying silencing in social cognition. The first advance involves the effect of practical interests on knowledge representation. Stakes effects on epistemic evaluations have been demonstrated in different narrative contexts, but perhaps the most famous involve what are known as "bank case" thought experiments in the contextualist literature [DeRose 1992, 2005]. The thought experiments involve a couple facing financial threats. In the "low threat" case, the couple wishes to deposit a check, but it is not very important if they are wrong about the bank's hours because they have plenty of money in their bank account. In a corresponding "high threat" case, however, they face many overdue bills and angry creditors, making it very important that they are correct about when the bank is open. Philosophers argue that it is harder to know when facing these high threats than low threats and, subsequently, that people will be more likely to say that it is true the couple knows the bank will be open when there is no threat than when the financial threat is high.

This prediction has been confirmed by experimental studies on epistemic judgments across a range of cases [Turri 2017]. ${ }^{2}$ In one study, for example, researchers found that financial threats in bank cases had a striking impact on epistemic evaluations [Turri 2017: Experiment 1]. When presented with versions of the bank case, participants

${ }^{2}$ For studies that do not find robust stakes effects in bank cases see Buckwalter [2010] and Rose et al. [2017]. 
agreed that the protagonists did know the bank would be open in a low threat case. However, they also agreed with the complete opposite sentence in the high threat case, or that the protagonists did not know the bank would be open. Moreover, the research also demonstrated that the financial threats had a profound impact on a broad range of other evaluations beyond knowledge. For instance, participants were more likely to attribute the belief that the bank was open to protagonists in the low threat case than the high threat case. They rated the evidence the protagonist had that the bank was open as stronger in the low threat case than the high threat case. The effect of heightened threats even led participants themselves to doubt that it was open in the first place. In other words, financial threats affected almost everything about the way participants perceived of this situation including what was true, as well as the way they represented the protagonist's evidence, beliefs, and knowledge.

The second empirical advance relevant to understanding silencing involves the mechanism and causal pathway by which practical interests impact knowledge judgments. Advancing on past work, this research shows that practical interests can cause judgments about how to act in a situation, and that, in turn, these actionability judgments can cause judgments about what is known [Turri, Buckwalter, and Rose 2016: 215]. In one study, for example, researchers presented participants with the following low threat or high threat case (distinguished in the brackets below):

Jennifer is an intelligence analyst developing a file on Ivan, an elusive foreign operative. Jennifer has a source who tells her that Ivan stopped [his low-carb diet/selling arms to terrorists] and is no longer [jogging regularly/a threat]. Jennifer must submit a [provisional/final] report on Ivan to her supervisor within the hour. 
She will [definitely/definitely not] have a chance to revise her [provisional/final] report, and she [will not/will] be held accountable for decisions based on her [provisional/final] report.

Researchers then asked participants to evaluate a series of statements regarding the low or high threat case. In the low threat condition, for example, participants evaluated whether "It's true that Ivan no longer jogs regularly," whether "Jennifer thinks that Ivan no longer jogs regularly," whether "Jennifer has good evidence that Ivan no longer jogs regularly," whether "Jennifer should write in the report that Ivan no longer jogs regularly," and finally, whether Jennifer knows that Ivan no longer jogs regularly." Participants in the high threat conditions answered the same questions where "jogs regularly" was replaced with "is a threat".

Entering these judgments into a causal search algorithm, researchers found that judgments about actionalibity concerning what the protagonist should write in the file had a significant effect on epistemic judgments. Specifically, in the best fitting causal model of these data, actionability judgments directly caused their judgments about knowledge, evidence, and truth. This model is depicted in Figure 1, where "stakes" corresponds to the independent variable of low or high threats, and "actionability", "knowledge", "truth", and “evidence" corresponds to dependent variables. 


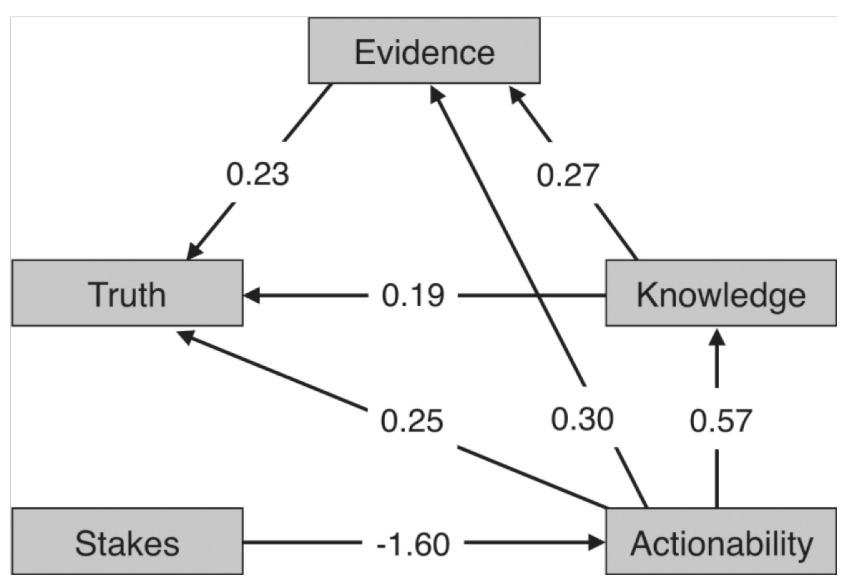

Figure 1. Reprinted from Turri, Buckwalter, and Rose [2016: 217], with permission: "Graph of the best fitting model as determined by a causal search using the Greedy Equivalence Search algorithm. Arrows represent directional causal pathways. Path coefficients represent the causal relation's strength and quality. Positive numbers represent a positive causal relation (higher scores for the cause generate higher scores for the effect; lower scores for the cause generate lower scores for the effect); negative numbers represent a negative causal relation (higher scores for the cause generate lower scores for the effect; lower scores for the cause generate higher scores for the effect)."

When trying to figure out how to act in a situation, one approach might be to first figure out what is known to be true, and then on the basis of that judgment decide a proper course of action as a result. But the present findings suggest that the opposite actually sometimes happens. We first recruit judgments about how to act in a situation and then use this determination to decide what is known, and subsequently, other epistemic evaluations regarding what is true or the quality of evidence. 
The results are directly relevant to understanding the link between silencing and knowledge. In this particular experiment, the actionability judgments that caused knowledge judgments concerned what the protagonists should communicate. In other words, the more something was viewed as communicable, the more likely it was viewed as known. This suggests that judgments about action, and particularly, judgments about what someone should say are connected to and can sometimes directly cause judgments about what others know. In fact, the causal connection between what should be communicated and knowledge was the strongest causal relationship measured between variables in the experiment.

To review, research from experimental cognitive science demonstrates that practical interests can have widespread effects on epistemic judgments. For example, in certain cases involving financial threats, we are less likely to represent others as knowing. Additionally, these threats can also impact the perceived quality of the evidence one has for a claim, whether we think something is actually true, and whether one forms a belief about it in the first place. Lastly, and most importantly, the research suggests a pathway for the effect of practical interests on knowledge representation. According to this pathway, practical interests affect knowledge representation due to the direct causal link between communication and knowledge judgments. In particular, judgments about what someone should say can directly cause judgments about what we think they know.

\section{Silencing Causes Knowledge Representation}

According to the causal model of epistemic injustice, silencing does not just follow as a symptom of certain epistemic representations, but can cause them to occur. Research from 
experimental cognitive science has demonstrated that actionability affects epistemic assessments including how we represent the knowledge of others. Specifically, this research demonstrates a direct connection between communicative acts and knowledge judgments, in particular. Putting these pieces together, findings support the causal model of epistemic injustice across several types of silencing. In what follows, I describe how locutionary, illocutionary, and perlocutionary forms of silencing can impact knowledge representation and result in epistemic injustice as a result of this mechanism.

Locutionary silencing occurs when individuals are deterred from speaking because they are threatened with serious consequences of even uttering words. Researchers have shown that serious consequences for action can negatively impact knowledge attribution, as well as estimations of truth, belief representation, and evidence assessments. Given these findings, the causal model predicts that locutionary silencing can cause underrepresentation of knowledge when knowledge attribution is negatively impacted by practical interests. The latter insight is due to Jason Stanley, who argues in his analysis of propaganda that "those who are placed by structural features of society in high-stakes situations in competing for goods are at an epistemic disadvantage" [Stanley 2015: 256]. If having more at stake sometimes decreases knowledge attribution, and there is more at stake for the disadvantaged, then this could create a series of complex epistemic barriers for the disadvantaged. Building on this insight in the present case, the research above extends this line of inquiry by linking knowledge attribution and the costs of communication, specifically. Locutionary silencing hinders action when threats to an individual for speaking are severe. A speaker might be silenced in this way, for example, when facing threats involving litigation, job loss, or physical assault for reporting that a crime has been 
committed. All else equal, we can expect speaking in silenced contexts to be less actionable than similar contexts in which silencing did not occur. In turn, judgments about what is or is not actionable can decrease epistemic evaluations including knowledge representation in social cognition. In particular, research has shown that judgments about someone should say impact a series of evaluations about them including what is known. Given these effects, we can expect that silenced individuals will be less likely viewed as holding true beliefs, having good evidence, and possessing knowledge than individuals who are not. In this way, locutionary silencing can cause underrepresentation of knowledge compared to those that are not subjected to conditions of silencing. Of course, the result is highly unjust because epistemic judgments are due to the conditions created for the purposes of manipulating speakers in the first place.

This model connecting communicative acts to knowledge representation suggests a subtle and perhaps unconscious way that epistemic injustice can occur through silencing in theory of mind. According to this model, for example, observers who had nothing to do with threatening a speaker can still be complicit in the epistemic harms to that speaker when they are locutionarily silenced. If judgments about what is actionable to communicate are connected to knowledge representation in theory of mind, then it is likely that we regularly recruit information about practical situations when making epistemic evaluations and knowledge judgments. When evaluating agents under threat of silencing, we can expect observers will be less likely to think that a subject in a less actionable situation has knowledge, good evidence, or true beliefs than subjects in situations in which silencing does not occur. Listeners may not always recognize or be appropriately sensitive to the fact that the perpetrators of silencing are causally responsible for creating these conditions. In 
this way, the greater community of listeners can contribute to the negative effects of silencing by underrepresenting knowledge even when they are not directly responsible for creating the conditions of silencing.

Similarly, perlocutionary silencing also causes epistemic injustice through the effect of actionability on knowledge representation. Perlocutionary silencing influences our evaluations of actions by decreasing whether perlocutions such as convincing, informing, or alerting, are seen as actionable. Decreased actionability judgments can cause decreased knowledge representation. Therefore, we can expect perlocutionary silencing to decrease knowledge representation compared to those who are not silenced. To illustrate the link between failed perlocutions and knowledge representation, consider the following example involving failed performance. Suppose, by way of analogy, that you are trying to figure out whether or not I know how to drive a car. You observe that I engage in several failed attempts to drive involving accidents and major traffic violations. No doubt this evidence would lead to the judgments that I am a poor driver, that I should not get behind the wheel, and furthermore, that I do not know how to drive. In a similar fashion, the observation that someone is unsuccessful at performing basic communicative acts, as in cases of perlocutionary silencing, can be misconstrued as evidence for their ignorance. After a period of failing to have the intended effects on an audience, one might come to doubt whether silenced individuals can or should perform certain communicative acts, such as alert, inform, or even persuade listeners concerning a certain proposition. Whether or not an individual should perform these acts, in turn, negatively impacts our evaluations of whether the proposition associated with these acts is known. Since communicative acts are more likely to be successful when silencing does not occur, this suggests that knowledge 
is less likely to be associated with individuals when they are silenced. This result is again unjust because the communicative goals of silenced individuals fail precisely because they face challenges to perlocutionary success that are not imposed to other individuals outside of these contexts. Returning to the driving analogy, this would be like inferring that I do not know how to drive on the basis of observing failed attempts, while neglecting to notice that they were the result of someone sabotaging the car.

To further illustrate this point, imagine a hypothetical case about perlocutionary failure, where Bill makes a credible assertion, presenting good evidence for the reality of climate change, but try, as he might, cannot persuade his audience, Don, it is true. Don isn't persuaded, and from his perspective comes to think that "Bill doesn't know what he's talking about". It's clear from Bill's inability to persuade Don that persuasion is not actionable. Judgments about what is actionable can cause judgments about what is known. And so, failure to successfully persuade Don may be perceived as evidence for Bill's ignorance. After all, being able to persuade someone with such good evidence in many contexts often is actionable in that way. But in silenced contexts that lack minimal appropriate conversational cooperation, it isn't. Don neglects to notice that perlocutionary failure can be explained by the fact that Don does not extend basic communicative charity or cooperation to Bill when hearing his arguments. When overlooking that detail, perlocutionary failure can be perceived as evidence for ignorance, rather than as a result of perlocutionary silencing.

Finally, illocutionary silencing also causes epistemic injustice as a result of the connection between actionability and knowledge representation. Illocutionary silencing decreases which illocutions are actionable. For example, consider again the case in which 
unjust laws prevent certain people from marrying by stopping "I do" from counting as a legal promise, or voting by stopping "yea" from casting a legal ballot. The less something is viewed as actionable, the less likely it will be viewed as being known. And such laws are specifically designed to prevent illocutionary action. As a result of this, observations of unsuccessful illocutionary action, in this case, not being able to make a legal promise or vote, may be misconstrued as evidence of ignorance about, say, the actual nature of voting or marriage. The result is again highly unjust because actionability is limited in this case as a result of unjust laws, irrespective of what a speaker actually knows about marriage or voting.

\section{Silencing and Ignorance}

Silencing can cause us to misrepresent the knowledge of others when they are unable to complete speech and communicate acts. This effect on mental state representation in theory of mind suggests how silencing can be a cause of epistemic injustice on the psychological level. But epistemic injustice through silencing may run deeper still, beyond just knowledge representation on the psychological level. In some cases, silencing may also contribute to epistemic injustice by not only causing us to misrepresent the knowledge others rightfully have, but by potentially causing ignorance and depriving others of knowledge itself.

How can stopping someone from speaking or communicating affect what someone actually knows, rather than just what we think they know? The answer to this question depends on the details of the correct theory of knowledge. On most traditional analyses in epistemology, though, knowledge is said to require justified true belief. From this 
definition, one widely, though not universally accepted epistemic principle is that knowledge requires belief [Armstrong 1969; Lehrer 1974; Buckwalter, Rose, and Turri 2015]:

Belief Entailment: If $\mathrm{S}$ knows that $\mathrm{p}$, then $\mathrm{S}$ believes that $\mathrm{p}$ According to this definition, an agent cannot know something is true if they do not believe it. Research in cognitive science has demonstrated that practical interests affect a broad range of judgments, including belief attribution to both others and ourselves (see Turri and Buckwalter [2017: Experiment 1]). As a result of this, we can expect that acts of silencing will discourage belief and belief attribution to others (relatedly, see Stanley [2015] and Fricker [2007] on self-confidence, and Cudd [1994] on oppression and coercion). If silencing can cause someone not to believe $\mathrm{p}$, and knowledge entails belief that $\mathrm{p}$, then on this definition of knowledge, silencing can literally cause ignorance that $\mathrm{p}$.

Similar results may follow for other leading, though more contentious theories of knowledge in contemporary epistemology. Consider for example, the theory of epistemic contextualism [DeRose 2009]. Contextualism is the linguistic theory that "knows" is a context sensitive expression. More specifically, the theory states that the standards required to truthfully say someone knows something are set by the context in which those statements are made. There may be many features of the conversational context that set this standard. Once such factor is practical consequences, for example, whether the costs associated with the bank being closed for an ascriber are low or high. The idea is that higher costs can shift the epistemic standard upwards making true knowledge statements false. According to epistemic contextualism, then, silencing may do more than just affect our judgments about knowledge. Rather, acts of silencing may also shift the conversational standard by which 
someone can truthfully say someone knows something (for criticism, see Buckwalter [2017] and Turri [2017]). In other words, silencing could take a previously true statement about what someone knows and make it literally false.

Silencing may also limit knowledge itself according to leading metaphysical theories of knowledge. According to some versions of pragmatism or interest relative invariantism, for example, whether or not a person has knowledge depends partially on what is at stake or what is actionable for them [Stanley 2005; Fantl and McGrath 2009]. These theories predict that practical costs associated with acting will sometimes make it harder for a subject to know things. Silencing can raise the costs associated with communicating. One implication of this theory, then, is that silencing makes it harder to have or retain actual knowledge [Stanley 2005, 2015]. Of course, interest relative invariantists are not committed to the claim that knowledge is always sensitive to practical interests in every circumstance or that they always decrease knowledge when they arise. But given that practical interests are frequently and perhaps predominately set in relation to social costs, and injustice is often the norm for the disadvantaged in many social interactions, we should expect a large proportion of the practical costs associated with communicative acts to stem from unjust features of social contexts. As a result of this, one potential consequence of the theory is that it seems to predict that the socially disadvantaged are in fact less knowledgeable (for a critical response, see Dotson [2018]).

These potential theoretical consequences mark several avenues for further research. It is an open theoretical question whether or to what extent theories which posit linguistic and metaphysical connections between knowledge and action allow the powerful to manipulate what is true to say about "knowledge" or what is actually known. To the extent 
that they do, one approach is to treat this as an objection or reason to reject such theories. Theorists have previously acknowledged that the idea that being in certain practical positions matters to the strength of an epistemic position could strike many as "madness" [Fantl and McGrath 2009: 28]. The fact that silencing can effectively manipulate action across many practical positions may serve as a particularly pointed example. After all, it might be thought, the consequence of speaking in such contexts "has no impact on your standing on any truth-relevant dimension" (ibid.), and further, that the problem with silencing is that it causes us to misrepresent, undervalue, or fail to recognize what the socially disadvantaged truly know, not that it renders them genuinely ignorant or their knowledge statements false. Alternatively, future research might take the opposite approach. It might be thought that epistemic contextualism or interest relative invariantism can shed unique light on the harms of silencing overlooked by prior accounts. According to these views, for example, it could be that silencing someone has the ability to reach into the linguistics or metaphysics of knowledge and literally change what they in fact know or the literal truth of what they say. Instead of serving as an objection to these theories, it might be thought, these shocking and disquieting theoretical implications may isolate precisely why silencing is so deeply epistemically unjust.

Lastly, the causal model of silencing may shed light on the origins of silencing in social practice and public policy. On the symptom model of epistemic injustice, silencing occurs as a consequence of prior epistemic representations. But given that silencing can also cause epistemic representations, it could be that these practices were developed as a form of epistemic control (relatedly, see Collins [2000: 3]). In other words, it could be that somewhere along the way the powerful implicitly recognized the connection between 
communication and knowledge, and adopted practices and policies to control speech acts precisely because it was a straightforward and effective means of controlling what people are classified by others as knowing or "knowledgeable", the literal truth of knowledge claims according to a conversational standard, or perhaps even what is actually known (relatedly, see also Hacking [1999: 34, 160]; Haslanger [2017] on "looping effects"). Such a recognition may begin to explain how epistemic injustice arose both as a byproduct of ordinary social cognition and how silencing continues as a structural phenomenon that promotes the systemization of certain kinds of oppression in the intellectual domain.

\section{Conclusions}

Silencing is the practice of interfering with speech and communicative action. Actionability judgments are an important aspect of epistemic judgments and can directly cause judgments about what others know. Expanding on prior accounts, research demonstrates this link extends from actionability to actionable communication and knowledge representation, specifically. This link supports the causal model of silencing, according to which silencing constitutes epistemic injustice by causing certain patterns of knowledge representation. On the psychological level, this suggests that silencing can cause epistemic injustice by causing us to represent what others know differently. The causal model is supported by a range of well replicated findings utilizing several experimental paradigms relating actionability, communication, and knowledge judgments. At the same time, there is no substitute for a direct test, and further research is necessary to test the causal model in contexts of oppression. 
Depending on the theory of knowledge one accepts, the causal model also suggests that silencing can cause epistemic injustice on a philosophical level. Silencing may not only cause us to misrepresent knowledge of others but also literally affect what is known or true to say about another's knowledge. Namely, the conditions brought about through silencing can potentially manipulate the conversational standard whereby knowledge statements come out false, or actually make it harder to have knowledge itself. If true, these theoretical consequences may potentially identify why silencing is distinctively epistemically unjust.

We began with the symptom model of epistemic injustice, in which silencing is a symptom of prior epistemic representations. This paper advances a causal model in which silencing is not only a symptom, but can cause epistemic representations of knowledge. Though the main focus of this paper is to defend the causal model, these two models of how epistemic injustice occurs are not mutually exclusive and perhaps complement each another. It is plausible that silencing can both result from prior epistemic representations and sometimes contribute to further epistemic representations. Moreover, given the close link between actionability and knowledge representation in ordinary judgment, it is reasonable to conjecture that these things might frequently blend together in actual practice. If this is correct, then it may suggest an even broader model of epistemic injustice that is cyclical in nature. According to this hypothesis, silencing and knowledge representation may go hand in hand in an ongoing cycle, with silencing causing certain patterns of knowledge representation, which in turn, results in and promotes more acts of silencing. Future research is needed to study this hypothesis in greater detail and to explore how a 
broader understanding of this kind of cyclical epistemic injustice might prevent negative effects of silencing.

Acknowledgments. For helpful feedback and discussion, I thank Carolyn Buckwalter, Shannon Dea, Jonathan Livengood, Rachel Ann McKinney, Kathryn Norlock, Jennifer Saul, and John Turri. Thanks also to two anonymous reviewers for useful comments and to Samir Chopra for inspiring this research. This research was supported in part by a Banting Fellowship awarded through the Social Sciences and Humanities Research Council of Canada.

\section{References}

Alcoff, Linda Martín 2012. Epistemic Identities, Episteme 7/2: 128-37.

Alston, William P. 2000. Illocutionary Acts and Sentence Meaning, London: Cornell University Press.

Anderson, Elizabeth 2012. Epistemic Justice as a Virtue of Social Institutions, Social Epistemology 26/2: 163-73.

Armstrong, D. M. 1969. Does Knowledge Entail Belief?, Proceedings of the Aristotelian Society 70/new series: 21-36.

Austin, J. L. 1975. How to Do Things with Words, Cambridge: Harvard University Press. Bird, Alexander 2002. Illocutionary Silencing, Pacific Philosophical Quarterly 83/1: 1-15. Bolinger, Renée Jorgensen 2017. The Pragmatics of Slurs, Nous 51/3: 439-62. 
Buckwalter, Wesley 2010. Knowledge Isn't Closed on Saturday: A Study in Ordinary Language, Review of Philosophy and Psychology 1/3: 395-406.

Buckwalter, Wesley 2017. Epistemic Contextualism and Linguistic Behavior, in The Routledge Handbook of Epistemic Contextualism, ed. Jonathan Jenkins Ichikawa, New York: Routledge: 44-56.

Buckwalter, Wesley, David Rose, and John Turri 2015. Belief through Thick and Thin, Nous 49/4: 748-75.

Buckwalter, Wesley, and Jonathan Schaffer 2015. Knowledge, Stakes, and Mistakes, Nous 49/2: 201-34.

Buckwalter, Wesley, and John Turri 2014. Telling, Showing and Knowing: A Unified Theory of Pedagogical Norms, Analysis 74/1: 16-20.

Cohen, Stewart 1999. Contextualism, Skepticism, and the Structure of Reasons, Philosophical Perspectives 13: 57-89.

Collins, P.H. 2000. Black Feminist Thought: Knowledge, Consciousness, and the Politics of Empowerment, New York: Routledge.

Cudd, Ann E. 1994. Oppression by Choice, Journal of Social Philosophy 25/s1: 22-44.

De Gaynesford, Maximilian 2009. Illocutionary Acts, Subordination and Silencing, Analysis 69/3: 488-90.

DeRose, Keith 1992. Contextualism and Knowledge Attributions, Philosophy and Phenomenological Research 52/4: 913-29.

DeRose, Keith 2005. The Ordinary Language Basis for Contextualism, and the New Invariantism, The Philosophical Quarterly 55/219: 172-98.

DeRose, Keith 2009. The Case for Contextualism, Oxford: Oxford University Press. 
Dotson, Kristie 2011. Tracking Epistemic Violence, Tracking Practices of Silencing, Hypatia 26/2: 236-57.

Dotson, Kristie 2014. Conceptualizing Epistemic Oppression, Social Epistemology 28/2: 115-38.

Dotson, Kristie 2018. Distinguishing Knowledge Possession and Knowledge Attribution: The Difference Metaphilosophy Makes, Philosophy and Phenomenological Research 96/2: 475-82.

Fantl, Jeremy, and Matthew McGrath 2009. Knowledge in an Uncertain World: Oxford University Press.

Finlayson, Lorna 2014. How to Screw Things with Words, Hypatia 29/4: 774-89.

Fricker, Miranda 2007. Epistemic Injustice: Power and the Ethics of Knowing, Oxford: Oxford University Press.

Hacking 1999. The Social Construction of What?, Cambridge, Massachusetts: Harvard University Press.

Haslanger, Sally 2017. The Sex/Gender Distinction and the Social Construction of Reality, in The Routledge Companion to Feminist Philosophy, eds. Ann Garry, Serene Khader and Alison Stone, New York: Routledge: 157-67.

Hawthorne, John 2004. Knowledge and Lotteries, Oxford: Oxford University Press.

Hornsby, Jennifer 1995. Disempowered Speech, Philosophical Perspectives 23/2: 127-47.

Hornsby, Jennifer, and Rae Langton 2009. Free Speech and Illocution, Legal Theory 4/1: 21-37.

James, William 1879 (1948). The Sentiment of Rationality, in Essays in Pragmatism, ed. A. Castell, New York: Hafner Press. 
Langton, Rae 1993. Speech Acts and Unspeakable Acts, Philosophy \& Public Affairs 22/4: 293-330.

Langton, Rae 1998. Subordination, Silencing, and Pornography's Authority, in Censorship and Silencing: Practices of Cultural Regulation, ed. Robert C. Post, Los Angeles: Getty Research Institute for the History of Art and the Humanities: 261-83.

Langton, Rae 2015. Accommodating Knowledge, The John Locke Lectures, Magdalen College, Oxford, May 13, 2015.

Lehrer, Keith 1974. Knowledge, Oxford: Clarendon Press.

Locke, John 1690 (1975). An Essay Concerning Human Understanding, ed. P. H. Nidditch, Oxford: Clarendon Press.

MacKinnon, Catharine 1987. Feminism Unmodified, Cambridge: Harvard University Press.

Maitra, Ishani 2009. Silencing Speech, Canadian Journal of Philosophy 39/2: 309-38.

Maron, Dina Fine 2017. Trump Administration Restricts News from Federal Scientists at USDA, EPA. Scientific American, URL = $<$ https://www.scientificamerican.com/article/trump-administration-restricts-newsfrom-federal-scientists-at-usda-epa/>.

May, Joshua, Walter Sinnott-Armstrong, Jay G. Hull, and Aaron Zimmerman 2010. Practical Interests, Relevant Alternatives, and Knowledge Attributions: An Empirical Study, Review of Philosophy and Psychology 1/2: 265-73.

Mcgowan, Mary Kate 2003. Conversational Exercitives and the Force of Pornography, Philosophy and Public Affairs 31/2: 155-89. 
McGowan, Mary Kate, and Ishani Maitra 2009. On Racist Hate Speech and the Scope of a Free Speech Principle, Canadian Journal of Law and Jurisprudence 23/2: 343-72.

Origgi, Gloria 2012. Epistemic Injustice and Epistemic Trust, Social Epistemology 26/2: 221-35.

Peet, Andrew 2017. Epistemic Injustice in Utterance Interpretation, Synthese 194/9: 342143.

Pinillos, N. Ángel 2012. Knowledge, Experiments and Practical Interests, in New Essays on Knowledge Ascriptions, eds. Jessica Brown and Mikkel Gerken: Oxford University Press: 192-219.

Rose, David, Edouard Machery, Stephen Stich, Mario Alai, Adriano Angelucci, Renatas Berniūnas, Emma E. Buchtel, Amita Chatterjee, Hyundeuk Cheon, In-Rae Cho, Daniel Cohnitz, Florian Cova, Vilius Dranseika, Ángeles Eraña Lagos, Laleh Ghadakpour, Maurice Grinberg, Ivar Hannikainen, Takaaki Hashimoto, Amir Horowitz, Evgeniya Hristova, Yasmina Jraissati, Veselina Kadreva, Kaori Karasawa, Hackjin Kim, Yeonjeong Kim, Minwoo Lee, Carlos Mauro, Masaharu Mizumoto, Sebastiano Moruzzi, Christopher Y. Olivola, Jorge Ornelas, Barbara Osimani, Carlos Romero, Alejandro Rosas Lopez, Massimo Sangoi, Andrea Sereni, Sarah Songhorian, Paulo Sousa, Noel Struchiner, Vera Tripodi, Naoki Usui, Alejandro Vázquez del Mercado, Giorgio Volpe, Hrag Abraham Vosgerichian, Xueyi Zhang, and Jing Zhu 2017. Nothing at Stake in Knowledge, Nous doi:10.1111/nous.12211.

Sripada, Chandra Sekhar, and Jason Stanley 2012. Empirical Tests of Interest-Relative Invariantism, Episteme 9/1: 3-26. 
Stanley, Jason 2005. Knowledge and Practical Interests, Oxford: Oxford University Press.

Stanley, Jason 2015. How Propaganda Works, New Jersey: Princeton University Press.

Tuana, Nancy 2009. The Speculum of Ignorance: The Women's Health Movement and Epistemologies of Ignorance, Hypatia 21/3: 1-19.

Turri, John 2012. Pyrrhonian Skepticism Meets Speech-Act Theory, International Journal for the Study of Skepticism 2/2: 83-98.

Turri, John 2013. The Test of Truth: An Experimental Investigation of the Norm of Assertion, Cognition 129/2: 279-91.

Turri, John 2016a. Knowledge and the Norm of Assertion: An Essay in Philosophical Science, Cambridge, UK: Open Book Publishers.

Turri, John 2016b. Vision, Knowledge, and Assertion, Consciousness and Cognition 41: 41-9.

Turri, John 2017. Epistemic Contextualism: An Idle Hypothesis, Australasian Journal of Philosophy 95/1: 141-56.

Turri, John, and Wesley Buckwalter 2017. Descartes's Schism, Locke's Reunion: Completing the Pragmatic Turn in Epistemology, American Philosophical Quarterly 54/1: 25-46.

Turri, John, Wesley Buckwalter, and David Rose 2016. Actionability Judgments Cause Knowledge Judgments, Thought 5/3: 212-22.

Unger, Peter 1975. Ignorance: A Case for Skepticism, Oxford: Oxford University Press. West, Caroline 2003. The Free Speech Argument against Pornography, Canadian Journal of Philosophy 33/3: 391-422. 
Wieland, Nellie 2007. Linguistic Authority and Convention in a Speech Act Analysis of Pornography, Australasian Journal of Philosophy 85/3: 435-56.

Williamson, Timothy 2000. Knowledge and Its Limits, Oxford: Oxford University Press.

Zhang, Sarah 2017. Looking Back at Canada's Political Fight over Science. The Atlantic, URL $=<$ https://www.theatlantic.com/science/archive/2017/01/canada-war-onscience/514322/>. 